\title{
INVESTIGANDO O AUTISMO: TEORIA DA MENTE E A ALTERNATIVA FENOMENOLÓGICA
}

Investigating autism: Theory of mind and the phenomenological alternative

Investigando el autismo: Teoría de la mente y la alternativa fenomenológica

\author{
Rossano Cabral Lima \\ Universidade do Estado do Rio de Janeiro
}

\begin{abstract}
RESUMO
Nos debates contemporâneos sobre o autismo, a "Teoria da Mente" entende que as principais características autistas resultam da falha nas capacidades de metarrepresentação, tornando impossível a compreensão dos estados mentais alheios. Este artigo tem como objetivo realizar o estudo crítico do paradigma cognitivo, e contrapor a este as contribuições da fenomenologia. Pesquisadores nesse campo sustentam que pensamentos, emoções e intenções já são expressos e compreendidos nas condutas explícitas, permitindo a sintonia mútua que funda a sociabilidade humana. Desta forma, no caso do autismo, antes da instalação de prejuízos na metarrepresentação, haveria distúrbios precoces na dimensão sensório-motora, interferindo nos processos de intersubjetividade primária e secundária. Concluímos que a perspectiva fenomenológica permite a crítica das noções de módulos mentais e dos modelos computacionais, destacando a experiência mental corporificada, pré-reflexiva e intersubjetiva, contribuindo assim para uma nova compreensão dos modos autistas de sofrer e experimentar o mundo.
\end{abstract}

Palavras-chave: Autismo; Cognitivismo; Teoria da mente; Fenomenologia

\begin{abstract}
In contemporary debates about autism, "Theory of Mind" considers the main autistic features as a failure in meta-representation, making it impossible to understand the mental states of others. This article aims to carry out the critical study of the cognitive paradigm and to introduce the contributions of phenomenology. Researchers in this field hold that thoughts, emotions and intentions are already expressed and understood in explicit behaviors, supporting the mutual attunement that underlies human sociability. Thus, in the case of autism, before the onset of problems in the metrepresentation, there would be early disturbances in the sensorimotor dimension, interfering in processes of primary and secondary intersubjectivity. We conclude that phenomenological perspective allows the critique of notions of mental modules and computational models, highlighting the embodied, pre-reflective and intersubjective mental experience, thus contributing to a new understanding of the autistic ways of suffering and experiencing the world.
\end{abstract}

Key words: Autism; Cognitivism; Theory of mind; Phenomenology 


\section{RESUMEN}

En los debates contemporáneos sobre el autismo, la "Teoría de la mente" entiende que las principales características autistas resultan del fracaso en las capacidades de metarrepresentación, haciendo imposible la comprensión de los estados mentales de los demás. Este artículo tiene como objetivo realizar el estudio crítico del paradigma cognitivo, y contraponer a éste las contribuciones de la fenomenología. Los investigadores en este campo sostienen que pensamientos, emociones e intenciones ya se expresan y se entienden en las conductas explícitas, permitiendo la sintonía mutua que funda la sociabilidad humana. De esta forma, en el caso del autismo, antes del início de las dificultades en la metarrepresentación, habría disturbios precoces en la dimensión sensorio-motora, interfiriendo en los procesos de intersubjetividad primaria y secundaria. Concluimos que la perspectiva fenomenológica permite la crítica de las nociones de módulos mentales y de modelos computacionales, destacando la experiencia mental corporificada, pre-reflexiva e intersubjetiva, contribuyendo así a una nueva comprensión de los modos autistas de sufrir y experimentar el mundo.

Palabras clave: Autismo; Cognitivismo; Teoría de la mente; Fenomenología

\section{INTRODUÇÃO}

Nas últimas décadas, a metáfora do "computador cognitivo" vem ganhando força no estudo dos fenômenos mentais, reforçando a ligação entre cognição e cérebro. De um lado, a neurociência cognitiva lança mão da explicação bottom-up, na qual a busca por áreas ou processos cerebrais precede a identificação dos processos mentais ou comportamentais aos quais elas se associariam. De outro, a neuropsicologia cognitiva abraça a abordagem topdown, pela qual primeiro ocorre a teorização sobre as estruturas ou módulos da cognição, e só depois a tentativa de localizá-los no cérebro (Nadesan, 2005). Seja na visão predominante, na qual módulos cognitivos delimitados processam a informação e estocam a memória, seja na visão conexionista, que coloca ênfase na noção de rede, o computador cognitivo se encarnará no cérebro e encontrará sua mais perfeita expressão no referencial da Teoria da Mente (ToM).

Desde os anos 1980, a ToM vem ganhando destaque dentre os modelos psicológicos de compreensão do autismo, fenômeno simultâneo ao significativo aumento em sua prevalência, cuja explicação ainda é controversa (Elsabbagh M. et al., 2012; Hill, Zuckerman e Fombonne, 2014). Apesar da hegemonia cognitivista, a tradição fenomenológica vem sendo resgatada nos últimos anos, no intuito de escapar ao reducionismo racionalista e de introduzir a dimensão corporal e a experiência em primeira pessoa num campo teórico no qual predominam a concepção modular do mental e o paradigma do funcionamento computacional.

Tomando como referência o período compreendido entre as décadas de 1980 e 2000, no qual a Teoria da Mente surgiu e alcançou certa hegemonia no campo das teorias psicológicas sobre o autismo, nosso objetivo é realizar um estudo crítico do paradigma 
cognitivo - particularmente da ToM -, tendo como base seus principais expoentes, como Simon Baron-Cohen, Alan Leslie, Uta Frith, Helen Tager-Flusberg e Ami Klin, e apresentar, como contraponto, as contribuições fenomenológicas de Dan Zahavi, Josef Parnas, Victoria McGeer e Shaun Gallagher. Esses autores vêm proporcionando um arejamento dos debates sobre a cognição ao destacar a experiência mental pré-reflexiva e intersubjetiva, possibilitando a inclusão da dimensão corporal no estudo da vida subjetiva, especialmente em seus períodos mais precoces, sem recair reducionismo fisicalista. A fenomenologia, assim, tem conduzido a uma releitura do autismo que pode ser útil na superação das tradicionais dicotomias entre mente e corpo, cérebro e psiquismo, cognição e afetividade, fazendo avançar a teorização e a clínica dos Transtornos do Espectro do Autismo (TEA).

\section{O AUTISMO COMO DÉFICIT DA METARREPRESENTAÇÃO}

Em meados dos anos 1980, ao indagarem se as crianças autistas possuíam a teoria da mente, Baron-Cohen, Leslie e Frith (1985) estabeleceram os fundamentos da mais fértil tese cognitiva sobre o funcionamento do psiquismo autista. Assim como Kanner encontrara na incapacidade precoce em se relacionar o ponto distintivo da psicopatologia do autismo, esses autores descreveram o que Ihes pareceu ser o prejuízo fundamental da cognição dessas crianças: a impossibilidade de atribuir crenças aos outros e, em consequência, prever os comportamentos alheios. Sua tese se baseava em um experimento simples. Vinte crianças autistas, 14 com síndrome de Down e 27 clinicamente normais foram apresentadas a uma história protagonizada por duas bonecas, Sally e Anne (Figura 1). Sally colocava uma bola numa cesta, sob a observação de Anne, e saía da sala. Durante sua ausência, Anne transferia a bola da cesta para uma caixa ao lado. Quando Sally retornava, as crianças tinham que responder onde ela procuraria a bola. Ao contrário das crianças com Down e das normais, a maioria das autistas apontou para a caixa. A conclusão foi a de que essas últimas não conseguiam separar o que elas próprias sabiam daquilo que Sally sabia ou, dito de outra maneira, não levaram em conta que a crença da boneca, mesmo falsa, era de que a bola continuava na cesta.

A hipótese dos autores, assim, era a de que elas eram inaptas em representar estados mentais, imputar crenças e prever as condutas dos outros. Faltava-Ihes, então, a capacidade de elaborar uma "teoria da mente"1 que lhes permitisse entender que pessoas queriam, sentiam, acreditavam e sabiam. As crianças com Down serviram de "grupo controle" no experimento, visando excluir a possibilidade de que o déficit mostrado pelos autistas fosse

\footnotetext{
${ }^{1}$ Baron-Cohen e colegas tomaram emprestada a expressão "teoria da mente" dos etólogos Premack e Woodruff, que no final dos anos 1970 realizaram experimentos para investigar se os chimpanzés seriam "mentalistas", e não behavioristas (Premack; Woodruff, 1978).
} 
resultado de retardo mental. Como $86 \%$ das primeiras passaram no teste (contra $85 \%$ das normais e apenas $20 \%$ das autistas), isso poderia ser descartado.

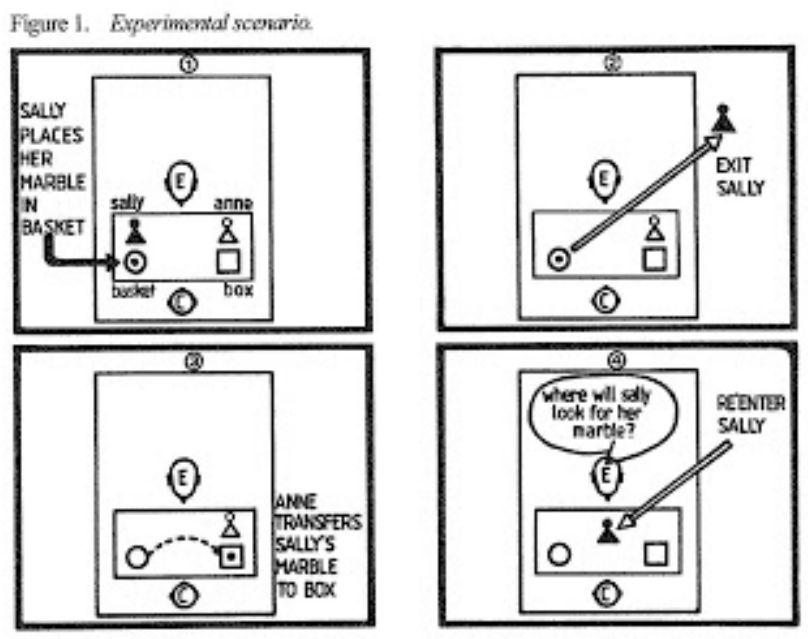

Figura 1: Teste Sally-Anne (Baron-Cohen, Leslie \& Frith, 1985)

Leslie (1987) considerou os jogos de faz-de-conta como uma das mais precoces manifestações da aptidão em entender os estados mentais. Essa habilidade seria uma forma de agir "como se", na qual o agente reconhece a diferença entre a situação real e a representada na ação em curso, e nas crianças normais começaria a aparecer entre 18 e 24 meses de idade. Esse autor, baseado na noção de representação sustentada pela perspectiva cognitivista e computacional do "processamento de informações", postula que as habilidades envolvidas no faz-de-conta não envolveriam representações do mundo, mas representações de representações - ou seja, metarrepresentações - que dariam origem à capacidade de entender a própria cognição e a dos outros. A capacidade de metarrepresentar implicaria desde a aptidão de fingir e perceber o fingimento dos outros até a de entender estados como desejar e querer movendo suas próprias ações ou presentes por trás dos comportamentos dos parceiros. Dessa forma, a criança começaria a implementar ações que teriam como objetivo não apenas influenciar o comportamento, mas principalmente afetar os estados mentais dos outros.

Leslie se indagou como as evidências perceptuais poderiam levar a criança a dispor da ideia de estados mentais que não podem ser observados. O fato de que, entre dois e três anos, ela adquire um vocabulário mínimo de termos que fazem referência a esses estados, como saber, pensar, lembrar, fingir, sonhar e crer, forneceria uma pista para tal proeza. Porém, se isso the permite praticar o faz-de-conta com certa facilidade, leva mais tempo para que ela entenda noções como a da "falsa-crença". Só aos quatro anos ela 
consegue perceber os elementos relevantes para o surgimento da crença a respeito de algo, como no experimento Sally-Anne, citado acima. Apesar de já apresentar ideias claras sobre o modo como os estados mentais existem aos três anos, o passo seguinte, o de enxergar os estados mentais como entidades abstratas que podem ter causas e efeitos concretos, seria mais difícil para a criança.

E como esse processo ocorreria em crianças autistas? Nelas, o déficit na construção da "teoria da mente" apareceria na escassez de jogos de faz-de-conta e na dificuldade em usar e entender termos associados a estados mentais. Em um segundo experimento de Baron-Cohen, Leslie e Frith (1986), suas habilidades representacionais primárias, como entender o conceito de objeto e causalidade, haviam se mostrado relativamente preservadas, variando adequadamente com a idade mental, A dificuldade conclui Leslie (1987) - estaria no campo da metarrepresentação. A impossibilidade em metarrepresentar de modo adequado explicaria boa parte das inaptidões no funcionamento social, pois elas não conseguiriam compreender nem prever as condutas alheias com base em estados mentais.

Mais tarde, Baron-Cohen (1997) proporá uma metáfora visual para descrever tais prejuízos cognitivos dos autistas. A grave dificuldade na metarrepresentação e na metacognição, ou seja, em imaginar e interpretar os estados mentais de terceiros e os próprios, corresponderiam a falhas nas capacidades de "leitura da mente" (mindreading), levando a uma situação de "cegueira da mente" (mindblindness). Assim, atribuir "teoria da mente" às demais pessoas, colocar-se "no lugar do outro" e interagir socialmente a partir da decodificação dos sinais verbais e não verbais que o parceiro emite seriam habilidades improváveis em um autista.

A capacidade de leitura da mente teria, para o autor, base inata, biológica e modular. Essa visão supõe a existência do "módulo da Teoria da Mente" (Theory of Mind module, ou ToMM, em inglês) ao lado de diversos outros. Na verdade, a "revolução cognitiva" iniciada nos anos 1970 teria como um de seus principais marcos a postulação de que a mente humana é multimodular ${ }^{2}$, e que a arquitetura psicológica pode ser mapeada "como sistema de relações computacionais e como o sistema físico que implementa essas relações" (Tooby; Cosmides, 1997, p. xv). Os módulos teriam surgido para atender a demandas evolutivas e cada um deles poderia, com o desenvolvimento das neurociências, vir a ser localizado de modo mais exato no cérebro.

Segundo Baron-Cohen, os testes com autistas demonstram que o entendimento do estado epistêmico de crença lhes é difícil, como mostra a impossibilidade de compreender

\footnotetext{
2 Para Fodor (1983), os módulos estão associados às seguintes características: especificidade; operação obrigatória; acesso limitado às representações nele computadas; rapidez de processamento; encapsulamento da informação; respostas básicas ou "superficiais" (shallow outputs); arquitetura neural fixa; padrões específicos e característicos de mau funcionamento; curso ontogenético característico.
} 
as "falsas-crenças", evidente no experimento Sally-Anne e em outros. Nesses testes, eles não demonstraram problemas em entender a sequência das histórias - especialmente quando apenas a causalidade de eventos físicos estava envolvida - mas em entender crenças como causas de condutas. Alcançar o sentido de "saber" ou "conhecer" (knowing) mostrou-se um pouco mais fácil para as crianças autistas que o de "acreditar". Como resultado, as crianças autistas mostram, além dos prejuízos nas habilidades de fingir, enganar ou fazer-de-conta, dificuldades na compreensão de emoções. Embora consigam inferir que emoções possam ser causadas por situações ou pelo desejo do agente, não conseguem entender o surgimento de estados emocionais baseados na crença do agente, como a surpresa. Não sendo "leitores de mentes", também não podem compreender atos comunicativos como o sarcasmo e a ironia, que exigiriam a habilidade de enxergar as intenções que o agente esconde por trás de suas declarações verbais.

Por meio da análise de autobiografias de autistas e de experimentos de introspecção (nos quais um sinal sonoro indica o momento de "congelar" o fluxo mental e tomar notas sobre o conteúdo dos pensamentos e sentimentos), Frith e Happé (1999) sustentaram que no autismo haveria não apenas prejuízos na teoria de outras mentes, mas também em relação à própria mente, o que corresponderia à ausência de consciência introspectiva. Para as autoras, a atribuição de mente para os outros e para si requereriam a distinção entre representações do mundo físico (ou de primeira-ordem) e representações de estados mentais (ou de segunda-ordem). Se a "computação" de estados mentais se encontra avariada, a autoconsciência e o autoconhecimento ${ }^{3}$ podem ser tão limitados quanto a compreensão da mente das pessoas ao redor. Isso não implicaria, esclarecem as autoras, a ausência de estados mentais em autistas, mas no possível predomínio de representações de primeira ordem e na inabilidade de refletir sobre suas experiências. Em sua vida psíquica, pensamentos, memórias, vivências e percepções podem ser indistinguíveis. Além disso, a compreensão das próprias ações estaria prejudicada, pois, na ausência de consciência introspectiva, o autista não conseguiria distinguir entre atos voluntários e involuntários, nem justificar os motivos de suas ações. Essas dificuldades podem atrapalhar as tarefas que exijam reflexão consciente, flexibilidade e imaginação, mas ajudar em atividades repetitivas e rotineiras.

Da mesma forma, especulam as autoras, a incapacidade dos autistas em refletir sobre o que experimentam e atribuir significado emocional a tais experiências poderia explicar fenômenos sensoriais como a resposta anormal ao calor e ao frio, e a hiper ou hiposensibilidade ao som, à luz e ao toque. A percepção da dor também se mostraria

\footnotetext{
${ }^{3}$ Um dos problemas da tese de Frith e Happé (1999) é o uso indistinto entre os termos self-awareness, selfcounsciousness e self-knowledge, o que será criticado por Zahavi e Parnas (2003). Neste artigo, traduzimos os dois primeiros por autoconsciência e o último por autoconhecimento.
} 
diminuída, pois, segundo Frith e Happé (1999), "a pessoa autoconsciente reflete não apenas sobre a dor, mas também sobre a experiência da dor" (p. 11). Essa pessoa, ainda segundo as autoras, além de sentir dor, sentiria angústia ou tormento, mas o mesmo não ocorreria nos autistas. Entretanto, a regra quanto à diminuída autoconsciência teria uma exceção parcial, representada pelos portadores da síndrome de Asperger. Pertencem a esse grupo, em geral, aqueles autistas que conseguem passar nos testes de falsas-crenças e de aparênciarealidade. Se teoria da mente e introspecção são correlatas, eles também teriam melhor condição que os demais autistas de refletir sobre os próprios estados mentais.

\section{ALÉM DA TEORIA DA MENTE}

À medida que a teoria da mente se estabelecia como a principal concepção psicológica do autismo na literatura internacional, suas insuficiências também passaram a ser explicitamente apontadas em trabalhos do próprio campo cognitivo. Tager-Flusberg (2001), por exemplo, se dedicou ao "reexame" dessa tese, propondo modificações que ampliassem sua potência explicativa em relação ao autismo. Para essa autora, seriam três os principais problemas da hipótese do déficit na teoria da mente. O primeiro diria respeito à sua universalidade, pois uma minoria de autistas sempre passa nos testes de falsas-crenças. $O$ segundo envolveria a especificidade dos déficits em relação aos autistas, pois crianças cegas, surdas, retardadas, com distúrbios específicos de linguagem, e pessoas com esquizofrenia também falhariam, em taxas variadas, nos testes-padrão. O terceiro teria relação com as dificuldades em explicar os prejuízos que aparecem precocemente no autismo, muito antes da emergência da teoria representacional da mente. Para tentar superar tais limitações teóricas, a autora defendeu a necessidade de substituir a noção categorial da teoria da mente, - do tipo "tudo ou nada", algo que alguém tem ou não tem - pela noção desenvolvimentista, na qual a compreensão de falsas-crenças é apenas um momento de um processo que se inicia cedo.

Para Tager-Flusberg (2001), esse desenvolvimento, em crianças normais, remontaria ao período neonatal, representado pela imitação de expressões faciais e pela orientação do bebê na direção de estímulos humanos. As bases da capacidade de atribuir estados mentais a outros já estariam em ação no segundo ano de vida, e entre dois e três anos a habilidade de interpretar desejos e emoções estaria instalada. Os quatro anos de idade, época tomada como referência nos testes da teoria da mente, seria a idade em que apareceria o entendimento da noção de crenças e outros estados epistêmicos mais elaborados, mas a evolução da teoria da mente não se encerraria nesse momento. Após essa fase, surgem a compreensão mais sofisticada da ambiguidade e da ironia, o reconhecimento dos traços de personalidade alheios, o uso da intencionalidade para realizar julgamentos morais e o refinamento da capacidade de interpretar os estados emocionais e cognitivos das 
pessoas a partir de sutis modificações em suas expressões faciais. Tudo isso mostraria que a teoria da mente significa mais do que a compreensão representacional da mente, a qual seria apenas mais um passo no desenvolvimento do entendimento dos estados mentais.

Para Tager-Flusberg (2001), o "novo modelo" de teoria da mente deveria realizar a distinção entre dois componentes básicos: o social-perceptivo e o social-cognitivo. O primeiro apareceria precocemente e seria movido por motivos afetivos, especialmente a recompensa, ajudando o bebê a fazer julgamentos a respeito dos estados mentais alheios. Seu desenvolvimento seria independente de outros sistemas cognitivos, como a linguagem. O segundo componente se constituiria a partir do anterior, e teria relações estreitas com a memória de trabalho e a linguagem. Plenamente instalado aos quatro anos de idade, ele permitiria deduções sobre estados mentais como a intenção e a crença, baseadas na integração de informações oriundas da percepção e da sequência dos eventos no tempo.

Pelo modelo de Tager-Flusberg, o autismo envolveria um déficit básico nos sistemas neurocognitivos que sustentam o componente sócio-perceptivo. Também se poderia afirmar que aqueles autistas com prejuízos linguísticos ou baixo nível cognitivo têm limitações mais graves no componente sócio-cognitivo. Por outro lado, crianças com boa linguagem e habilidades cognitivas preservadas conseguiriam uma melhor evolução, inclusive passando nos testes de falsas-crenças. Redescrita dessa maneira, a teoria da mente poderia ser preservada como modelo explicativo potente para os transtornos do espectro autista, embora a autora ressalte que déficits em outras áreas cognitivas também devam estar envolvidos.

Klin, Jones, Schultz e Volkmar (2005) propõem uma leitura do fenômeno autista pelas lentes da "ciência cognitiva corporificada". Para esses autores, o modelo computacional dominante no campo das ciências cognitivas simplifica o mundo social na forma de "tarefas de domínio fechado" (closed domain task), nas quais um número limitado de testes facilmente aplicáveis substitui o ambiente da criança. Em seu lugar, propõem o modelo da "mente enativa" (enactive mind, ou EM), que enxerga o mundo como uma série de "tarefas de domínio aberto" (open domain task). Neste modelo, a adaptação social é vista como uma experiência sem regras previamente definidas, na qual a criança terá que discernir, em cada situação, entre o que lhe é importante e o que não é, a partir de seus desejos, percepções e objetivos, baseada na memória das experiências passadas.

Ao contrário do modelo computacional, que enxerga o mundo social como uma série de regularidades predeterminadas e vê na mente da criança vários "módulos" à espera de problemas para resolver, a EM é ativa e maleável, mudando a si mesma enquanto tenta agir e dar sentido ao mundo que encontra. Assim, um modelo de "cognição descorporificada" dá lugar à "cognição corporificada", na qual a mente carrega as marcas das ações do corpo no contato com o ambiente. Sempre regulada pela dinâmica da "saliência diferencial", a mente hierarquiza os objetos do mundo segundo o maior ou menor valor adaptativo para aquele 
organismo. Na lógica da sobrevivência do indivíduo e da espécie, é mais útil, por exemplo, dar valor especial às pessoas que aos objetos inanimados. Para a EM, essa "topologia da saliência" permite à criança distinguir o relevante do irrelevante, e só se instala a partir de ações perceptualmente guiadas visando à adaptação social.

Essa dinâmica da relevância estaria ausente da mente autista, apontam Klin et al. (2005). Se a criança normal "enacta" ou dota o ambiente de intencionalidade ativa, de modo a privilegiar pessoas e sinais corporais que the deem pistas de estados mentais, a criança autista "enacta" seu mundo de uma maneira bastante diferente, o que lhe leva a falhar em responder às demandas infinitamente variáveis que lhe são feitas pelos outros no dia-a-dia. Isso explicaria o motivo de seu mau desempenho em tarefas cotidianas "naturalistas", mesmo que tenha se saído bem em testes estruturados semelhantes, no ambiente controlado do laboratório.

Curiosamente, é nesse mesmo mundo laboratorial que os autores buscam simulações naturalistas em favor de sua hipótese. Usando tecnologia de "eye-tracking", que permite rastrear a direção do olhar enquanto se assiste a um filme, foram percebidas várias diferenças entre autistas adultos sem atraso cognitivo e 'controles' normais. Quando houve um enquadramento no rosto dos atores da película, os autistas preferiram se fixar na boca ou em regiões periféricas da face dos protagonistas, enquanto os não autistas procuraram o sentido da cena concentrando-se na região dos olhos - o que confirmaria as hipóteses de Baron-Cohen (1997) sobre a predominância do olhar no desenvolvimento da habilidade de leitura de mentes, ponto não desenvolvido por Klin et al. Em outra parte do estudo, ao serem apresentados a uma sequência com forte carga emocional (um beijo) e a um programa infantil popular, pessoas autistas dirigiram sua atenção para aspectos pouco relevantes do cenário, como um interruptor ou prateleiras no fundo da cena. Tudo isso mostraria a limitação no uso de pistas não verbais para compreender eficazmente o significado da cena social e comprovaria a hipótese central da EM de que o autismo inverte a hierarquia na qual os estímulos sociais são mais relevantes que os inanimados e na qual a face e os olhos têm predominância quando se quer entender a intencionalidade do outro. Autistas, segundo os autores, não seriam "especialistas em faces" ${ }^{4}$, expertise que os humanos normais adquiririam a partir de experiências relacionais recorrentes desde os primeiros meses de suas vidas.

A crítica da teoria da enação aos modelos computacionais se relaciona, em boa parte, à noção de representação neles embutida. Enquanto tais modelos concebem as representações como universais e independentes do contexto, nas quais símbolos serão manipulados como algoritmos na construção da mente social, a EM se indaga de que maneira

\footnotetext{
${ }^{4}$ Klin et al. (2005) referem-se aqui a experimentos que mostram que os autistas, quando expostos a faces humanas, ao invés de ativar o giro fusiforme, usam uma região do cérebro normalmente associada ao reconhecimento de objetos inanimados, o giro temporal inferior.
} 
a representação ganha sentido para a criança em suas experiências cotidianas. O simples manejo de um símbolo não garante seu uso social, como provam as ecolalias, ecopraxias, neologismos e hiperlexias autistas, todos idiossincráticos, sem sentido na linguagem compartilhada. A dissociação entre compreender o símbolo ou a instrução no ambiente de laboratório e saber como agir sobre eles nas situações do dia-a-dia permite a Klin et al. (2005) afirmar que as representações mentais são, na verdade, substitutos das ações que as geraram e que elas agora simbolizam. "Quando preservamos e manipulamos símbolos em nossas mentes, portanto, também estamos evocando a rede de experiências resultantes da história de vida de ações associadas com aquele símbolo" (p. 148), concluem os autores.

Assim, podemos dizer que no início estava o corpo, seu aparato sensório-motor, o ambiente e a memória das ações logradas, nascendo daí o aparato representacional cognitivo. As habilidades perceptivas, como a visão, deixam de ser o espelho interno a gerar modelos verídicos do mundo externo e tornam-se a recuperação ativa de informações úteis demandas pelo ambiente em tempo real. Nesse sistema de "percepção-pela-ação", apenas os processos perceptivos que foram gerados em íntima conexão com as necessidades da ação podem guiar as futuras ações. Portanto, para a EM, cognições, percepções e ações são normalmente inseparáveis, e é a "dinâmica da saliência" que faz as primeiras emergirem das últimas de uma maneira adequada e adaptativa.

No autismo, entretanto, a incapacidade precoce em distinguir o socialmente essencial do acessório revela a existência de uma solução de continuidade entre cognição e ação. O sistema representativo no autismo mostraria, assim, o que ocorre quando conceitos e linguagem são adquiridos fora do campo das ações sociais corporificadas, tornando o discurso e o comportamento artificiais e inadequados. Os prejuízos na habilidade de imitação apresentados pelos autistas seriam uma das principais manifestações do comprometimento de seu sistema de "percepção-pela-ação". Crianças autistas mostram uma plêiade de condutas ecolálicas e ecopráxicas, repetições aparentemente desprovidas de função, mas têm sérias dificuldades em aprender com tarefas e brincadeiras que requerem imitação. Para a EM, isso é um exemplo do desencaixe que elas operam entre os movimentos e o seu contexto social. Sem significado de troca emocional ou comunicativa, atos motores são apreendidos e repetidos de modo automático e estereotipado.

\section{A ALTERNATIVA FENOMENOLÓGICA}

As revisões e críticas feitas à teoria da mente no interior do campo cognitivo trouxeram ganhos à compreensão dos fenômenos autistas, especialmente por deslocar o foco para períodos anteriores à aquisição da capacidade de metarrepresentação. Essa ampliação de seu escopo, de certa forma, tem ajudado a teoria da mente a preservar a hegemonia nas pesquisas psicológicas sobre o autismo. Não nos parece, porém, que o modus operandi das 
ciências cognitivas possibilitem maiores ganhos do que aqueles que já foram alcançados, e qualquer avanço na apreensão teórica do autismo, principalmente nas etapas precoces da vida, precisa romper com sua epistemologia, o que não significa prescindir de todas as suas contribuições. A noção desenvolvimentista de Tager-Flushberg e o modelo da mente enativa e a noção de "cognição corporificada" apresentados por Klin et al., ao se posicionarem na fronteira do cognitivismo e romperem com o referencial modular-computacional, podem servir como ponto de contato entre o que há de melhor nos estudos cognitivos e a perspectiva de outra disciplina, a fenomenologia.

Abrangendo um conjunto diversificado de abordagens, a fenomenologia tem como objetivo descrever e compreender a estrutura da experiência mental corporificada (Gallagher; Zahavi, 2008). O campo fenomenológico, especialmente nos últimos anos ${ }^{5}$, vem esboçando alternativas à teoria da mente, em particular quanto aos sinais precoces do quadro. Para Zahavi e Parnas (2003), a questão fundamental é saber se os fenômenos da intersubjetividade e autoconsciência ${ }^{6}$ dependem da aquisição de teoria da mente. Os autores apresentam a teoria da mente dividida em duas vertentes: a simulação e a theorytheory. Para os adeptos da simulação, a compreensão dos outros é motivada por fatores emocionais, volitivos e práticos, e se baseia na habilidade de se projetar imaginariamente no psiquismo alheio. Para a maioria dos partidários da theory-theory - corrente que examinamos neste artigo, e que Zahavi e Parnas tomam como principal adversária - a atribuição de crenças aos outros envolve o emprego de conhecimento teórico, inato, forjado pela evolução e presente em módulos cerebrais desde o nascimento.

A theory-theory tenderia a negar que a compreensão dos estados mentais se deriva da experiência direta, os tratando como entidades não observáveis e postuladas teoricamente. Além disso, essa vertente se basearia no pressuposto paralelista de que o sujeito se utiliza do mesmo mecanismo teórico para ter acesso aos estados mentais dos outros e aos dele próprio, sendo sua evidência empírica extraída dos testes de falsas crenças e aparência-realidade. Para Zahavi e Parnas, esses testes mostrariam que a ausência de teoria da mente não seria necessária nem suficiente para a instalação do autismo. Crianças normais abaixo de quatro anos não teriam acesso a essa teorização, e nem por isso têm comportamentos sociais autistas; por outro lado, pacientes com Asperger podem ter sucesso nos testes, mas mesmo assim demonstram sinais autistas. Além disso, os sinais precoces do

\footnotetext{
${ }^{5}$ É preciso destacar, contudo, o pioneirismo do psiquiatra alemão Gerhard Bosch na abordagem fenomenológica do autismo. Publicado em alemão em 1962, seu trabalho foi traduzido para o inglês em 1970 como Infantile autism: a clinical and phenomenological-anthropological investigation taking language as the guide. BerlinHeildelberg-New York: Springer-Verlag, 1970. 158 p.
}

${ }^{6}$ Zahavi e Parnas (2003) privilegiam o termo self-awareness, que engloba um forma primitiva e outra reflexiva. A forma primitiva, segundo eles, equivaleria à chamada "phenomenal consciousness". 
quadro, aparecendo por vezes no primeiro ano de vida, mostrariam que o déficit presente não pode se localizar nas funções cognitivas mais altas.

Zahavi e Parnas (2003) defendem que autoconsciência não é sinônimo de consciência reflexiva. A ênfase da teoria da mente nessa última acabaria deixando de lado a consciência de si que é prévia à reflexão, acessada pela experiência em primeira pessoa, e que poderia ser resumida pela expressão 'what it is like'. Essa autoconsciência não existe separadamente da experiência, nem é algo que se acrescenta pela reflexão ou introspecção, mas é a própria consciência da experiência. Quanto à intersubjetividade, os autores afirmam que ela normalmente dispensa uma compreensão do outro baseada na previsão e explicação de seus estados mentais, pois o engajamento no mundo comum bastaria para que esse entendimento se instalasse. Isso porque, para a fenomenologia, a experiência afetiva e os estados mentais não são internos, teóricos e não observáveis, mas estão patentes no corpo, em suas ações e expressões, que já portam intencionalidade e sentido, permitindo que sua compreensão seja direta e pragmática.

Portanto, no cruzamento entre teoria da mente, autoconsciência e intersubjetividade, os autistas teriam consciência de si no sentido mais primordial, pois têm experiências do ponto de vista da primeira pessoa, podendo, entretanto, ter dificuldades no campo do autoconhecimento. Na verdade, apontam os autores, os relatos de autistas de alto funcionamento ou de Aspergers, ao contrário de evidenciar sua fraqueza na teoria da mente, mostrariam a excessiva dependência de uma teorização explicitamente elaborada, havendo falhas na compreensão mais imediata e implícita das regras das interações interpessoais. Temple Grandin, autista que hoje é professora do Departamento de Ciências Animais da Universidade do Estado da Califórnia, descreve bem como necessita de esforço consciente para entender as relações sociais:

Quando encontro uma situação social nova, eu tenho que buscar em minha memória uma experiência similar, que eu possa usar como modelo para minha próxima ação. À medida que preencho minhas bases de dados com um número maior de informações, eu lido cada vez melhor com situações sociais diferentes. Eu tenho que ensaiar como tratar a pessoa antes de interagir com ele ou ela. Eu tenho muitos problemas quando sou confrontada com surpresas sociais, não esperadas. Para interações sociais normais com clientes, eu uso respostas programadas e pré-ensaiadas. Tudo é feito com lógica. (...) Eu atualmente passo horas e horas tentando entender intelectualmente o sentido da vida. (Grandin, 2005, p. 1283). 
O tema da autoconsciência também é o centro da abordagem fenomenológica de McGeer $(2004)^{7}$. Em sua crítica à teoria da mente, a autora elege como alvo particular as hipóteses de Frith e Happé (1999) a respeito dos déficits na autoconsciência dos autistas, a partir de seus relatos autobiográficos. Para ela, a hipótese cognitiva equivaleria ao modelo neoperceptivo, no qual o conhecimento das próprias experiências e cognições se basearia na capacidade de introspecção, possibilitando os julgamentos sobre nossos conteúdos mentais. Nesse modelo, a relação entre as experiências - ou estados de primeira-ordem - e os julgamentos - ou estados de segunda-ordem - é independente e contingente, havendo uma lacuna entre ambos. Isso explicaria a suposta incapacidade dos autistas de refletirem de modo adequado sobre as próprias experiências sensórias, se enganando sobre o que se passa em suas mentes, o que permitiria a Frith e Happé considerarem a autoconsciência autista bastante limitada.

Para McGeer, ao analisar os relatos de autistas sobre as suas experiências, a concepção neoperceptiva encontraria diversas dificuldades, entre elas o problema da regressão a instâncias cada vez mais elevadas de representação. Para expressar fielmente os estados de primeira-ordem, seria necessário não apenas que os de segunda-ordem estivessem intactos, mas também o bom funcionamento de estados de terceira-ordem, ou seja, aqueles que refletem o conhecimento dos sujeitos sobre o seu conteúdo mental, nos quais seus relatos estão baseados. Sendo assim, se nos autistas os estados de segundaordem estão avariados, por que estariam intactos os de terceira-ordem, se ambos dependeriam dos mesmos mecanismos? Portanto, como confiar na fidedignidade dos relatos dos autistas sobre suas experiências? Estariam eles expressando o que "realmente" teriam experimentado? Esse problema se tornaria ainda mais acentuado quando se leva em conta que a maioria dos depoimentos autobiográficos, com o de Temple Grandin, é produzida por autistas de alto funcionamento ou 'Aspergers', nos quais certo grau de autoconsciência seria atingido por meio de um aprendizado compensatório.

Para a autora, a melhor saída para esses impasses seria interromper tal processo de regressão desde o seu início. Nesse sentido, propõe o modelo expressivista direto, no qual os relatos em primeira pessoa já expressam diretamente os estados de primeira-ordem. Por esse modelo, saber o que eu creio requer apenas que eu tenha conhecimento prévio sobre os requisitos do processo de crença, ou seja, a inclinação para julgar algo, e a capacidade de fazer e expressar julgamentos sobre quaisquer aspectos do ambiente. Dessa forma, o que chamamos de autorreflexão, referindo-se a sensações ou a estados intencionais, não requer a introspecção à maneira neoperceptiva, pois não envolve olhar "para dentro", e sim olhar "para fora", isto é, dirigir novamente a atenção para o mundo, mesmo que de maneira

\footnotetext{
${ }^{7}$ McGeer (2004), assim como Zahavi e Parnas (2003), privilegia o termo self-awareness, mas por vezes usa selfconsciousness com o mesmo sentido.
}

Rev. Nufen: Phenom. Interd. | Belém, 11(1), 194-214, jan. - abr., 2019. 
imaginativa ou mnêmica. Portanto, o alvo da atividade epistêmica é o mundo. A atividade autoconsciente reflexiva envolvendo estados intencionais como crenças, desejos ou medos, requer apenas que o sujeito domine os conceitos de crer, desejar ou temer, compreenda as regras que regem sua aplicação e os transmita em palavras com a finalidade de comunicar a experiência aos outros. A mesma abertura ao mundo está presente quando o que está em jogo é a experiência sensória:

Eu posso ser indagado sobre minhas experiências sensórias, porém, assim como no caso da crença, o único modo de avaliar o que eu estou realmente experimentado numa dada situação não é perscrutar internamente meus estados sensoriais; é mais focalizar minha atenção em como, nesse momento, as coisas cheiram, se parecem, têm sabor (...). (McGeer, 2004, p. 247).

Nesse modelo, portanto, a chamada "riqueza fenomênica da experiência" não diz respeito a um fenômeno - a experiência - independente e que daria acesso a real matriz da subjetividade, mas sim à própria riqueza do mundo que se percebe. A principal consequência do modelo experiencial é que, ao contrário do modelo neoperceptivo, não há dois níveis de subjetividade, pois não há distinção experiência-consciência. A consciência da experiência, nos relatos em primeira pessoa, é apenas minha habilidade de contar como as coisas se parecem para mim, a partir da minha percepção. É claro que haverá uma "consciência cognitiva" mais sofisticada, que pode permitir ao indivíduo reconhecer que o mundo pode não ser como parece à primeira vista, mas ela só aparecerá secundariamente.

Como se baseia nos relatos subjetivos e em sua natureza linguística, o modelo expressivista de McGeer admite a possibilidade de que os sujeitos possam se equivocar, se expressar mal, ter lembranças distorcidas, mas também, como seria o caso do autismo, experimentar o mundo de um modo confuso e bastante diferente da maioria das pessoas. Deveríamos, assim, considerar os autorrelatos dos autistas por seu valor de face, os tomando como expressões diretas de modos anormais de experiência. Não haveria nos autistas, como querem Frith e Happé (1999), diferenças entre a experiência da dor, que envolveria apenas processos de primeira-ordem, e a consciência da dor, que necessitaria da introspecção, sendo um estado de segunda-ordem - e também, pode-se acrescentar, entre ambos e o relato da dor, situado no nível da terceira-ordem. Somente ao levar a sério os relatos das experiências dos autistas, poderíamos, para McGeer, dar a devida importância às bases sensoriais de sua incapacidade precoce de relação com os outros, prejudicando ou impedindo as interações que têm relevância na aquisição das habilidades sociais e cognitivas posteriores, como aquelas necessárias para o aparecimento da teoria da mente. 
A crítica de Gallagher $(2004,2005)$ aos fundamentos da teoria da mente partilha dos mesmos princípios encontrados em McGeer. Para Gallagher $(2004,2005)$, tanto a theorytheory quanto a teoria da simulação são atravessadas por um "argumento pragmático forte", o de que a teorização precoce sobre a mente alheia será a base para todo o entendimento interpessoal subsequente. Sustentando esse argumento, haveria uma "suposição mentalística cartesiana", qual seja, a de que conhecer uma pessoa é sinônimo de conhecer sua mente, instância escondida internamente, que emprestaria intencionalidade às condutas que se exteriorizam corporalmente. Contudo, não sendo possível o acesso direto aos estados intencionais alheios, só se poderia conhecê-los a partir da postura teórica ou simulatória. A suposição mentalística exige, então, que a criança possua o conceito de crença, desejo ou intenção antes de poder atribuí-lo ao outro.

Para o autor, entretanto, é a percepção que esclarece o estado mental do outro, antes que uma teoria o faça. O diálogo entre dois indivíduos não exigiria um distanciamento abstrato em terceira pessoa na busca por explicações causais - especialmente se eles tiverem três ou quatro anos de idade. Se abrirmos mão da ideia de que as ações traduzem para o outro a mente subjacente, e entendermos que a intenção comunicativa é realizada ali, no próprio ato corporal de comunicação, é difícil sustentar um mecanismo de "leitura de mentes" nas origens da interação interpessoal. Nesse sentido, tanto a theory-theory quanto a teoria da simulação precisariam ser redescritas. Na simulação, o que estaria em jogo seria menos a projeção ou atribuição dos próprios estados mentais à mente do outro, e mais o ajustamento motor que me permite o insight do comportamento da pessoa com a qual interajo. Isso aproxima a simulação de uma habilidade praticada e a distancia de uma abordagem mental teórica.

Gallagher (2005) sustenta que, para a fenomenologia, "nosso modo primário e comum de estar no mundo é a interação pragmática, (caracterizada pela ação, envolvimento e interação baseados em fatores ambientais e contextuais) e não a contemplação mentalista ou conceitual" (p.212). Essa interação pragmática depende menos de mecanismos de explicação e mais de estratégias de avaliação. O que motiva a ação é algum aspecto da própria situação que a convocou, o modo como a pessoa a experimenta, dispensando um estado mental cognitivo fundacional. A capacidade de avaliação é pré-teórica e é o que permite que a criança pequena já consiga envolver-se em situações intersubjetivas. Mesmo quando tal capacidade se torna reflexiva, sempre estaremos tratando de uma reflexão arraigada nas ações possíveis, nunca em estados mentais isolados. Na verdade, a emergência da teoria da mente na criança não apareceria para substituir essa habilidade primária de avaliação, mas seria mobilizada para preencher suas insuficiências em situaçõesproblema. 
O principal ponto da crítica gallagheriana aos experimentos da ToM refere-se à pertinência da perspectiva da terceira pessoa para explicar interações em segunda pessoa. Nos testes, pede-se à criança para prever o que fará um personagem com o qual ela não está interagindo diretamente, e pretende-se que o resultado de tais exercícios no nível "eu-ele" seja aplicável às relações "eu-você" que caracterizam a maior parte das trocas cotidianas. $\mathrm{Na}$ verdade, mesmo as crianças de três anos que não passam nesses testes não demonstram dificuldades em compreender a questão colocada pelo pesquisador, com o qual estão experimentando uma genuína relação em segunda pessoa. Quando em testes de falsas crenças a criança autista demonstra entender que o personagem (como a boneca Sally) não sabe que o objeto está num local particular, mas ainda assim prevê que este o procurará lá, a teoria da mente trata isso como uma discrepância entre dois estados cognitivos. Para Gallagher, o mais correto seria dizer que a discrepância ocorre entre um estado cognitivo a respeito do conhecimento limitado do personagem e a compreensão de como este agirá. Isso comprova que, em situações normais, o acesso às crenças, desejos e intenções alheias é possível porque elas já estão presentes na conduta do interlocutor, o que é refletido em nosso próprio esquema de ação. Nenhum mergulho em crenças escondidas na mente do outro daria o que a percepção coloca à disposição desde muito cedo. Antes da instalação da capacidade de compreender teoricamente que o outro pode ter crenças iguais ou diferentes das que tenho, práticas sensório-motoras e não conceituais pavimentariam a habilidade social humana, e continuariam a representar nosso principal meio de acesso ao outro em etapas posteriores do desenvolvimento.

Nesse sentido, Gallagher (2005) estabelece quatro "condições pré-teóricas" para que a apreensão de mentes e ações - intencionais ou não - se instale:

1. a compreensão do que significa ser um sujeito que experimenta; 2. a compreensão de que certos tipos de entidades (mas não outros) no ambiente são tais sujeitos; 3. a compreensão de que essas entidades são de algum modos similares e de outro modo diferentes de si próprio, e 4. o conhecimento pré-teórico específico sobre o modo como as pessoas se comportam em contextos particulares. (p. 224).

Para entender as origens dessas condições, o autor acredita ser necessário distinguir intersubjetividade primária e intersubjetividade secundária ${ }^{8}$. A intersubjetividade primária envolveria capacidades sensório-motoras, ou seja, corporificadas, e de matiz emocional, que habilitam a criança a perceber as intenções alheias. $O$ senso

\footnotetext{
${ }^{8}$ Esses conceitos remontam aos trabalhos de Trevarthen (1977) e Trevarthen e Hubley (1978).
} 
primário do outro já estaria disponível de modo não conceitual desde os primeiros meses de vida, como demonstraria a perfeita habilidade de imitação observada em neonatos. Em relação às condições estabelecidas acima, a imitação dependeria da distinção entre self e não self e do senso perceptivo do próprio corpo, mas implica também o reconhecimento de que o outro é do mesmo tipo que eu. Tudo isso apontaria para uma intencionalidade corporal compartilhada entre o bebê e seu parceiro, que dispensa uma "teoria inicial" da ação ou a consulta de um plano mental interno por parte da criança.

O "estado mental" necessário para as habilidades imitativas seria simplesmente a reunião da disposição corporal de agir intencionalmente e a sensação fenomênica de como seria executar ("what is like to do") a ação. Dito de outra maneira, e tomando como exemplo a imitação de expressões faciais, o modelo visual (a face do outro na frente da criança) e o modelo proprioceptivo (a sequência de movimentos em seu próprio rosto) fornecem tudo o que o bebê precisa para imitar, não havendo um evento ideativo na mediação entre visão e propriocepção. Tudo já estaria inscrito no esquema corporal puramente pragmático, despido de qualquer qualidade representacional abstrata. A compreensão do estado emocional alheio não exige a leitura, atribuição ou simulação de estados mentais, mas já está lá, nos movimentos corporais do outro. (Gallagher, 2004; 2005)

Juntos, os fenômenos abarcados nas intersubjetividades primária e secundária comporiam o "pano-de-fundo hermenêutico" que possibilitaria as conquistas mentalistas conceituais posteriores. Mesmo quando estas últimas se instalam, são as primeiras - na verdade, mais a intersubjetividade primária do que a secundária - que continuam determinando as relações sociais.

Como consequência da noção de intersubjetividade, Gallagher (2004, 2005) propõe a "teoria interativa" do autismo, apostando que nessa patologia os problemas sensóriomotores surgiriam primeiro, e apenas depois apareceriam os prejuízos nas funções cognitivas específicas. O suporte empírico dessa teoria seria dado por estudos como os de Teitelbaum, Teitelbaum, Nye, Fryman e Maurer (1998), que mostram a presença de distúrbios do movimento (atrasos no desenvolvimento, assimetrias ou sequenciamento anormal) em vídeos de crianças mais tarde diagnosticadas como autistas, desde os primeiros seis meses de vida, envolvendo as habilidades de sentar, engatinhar e andar, dentre outras. Se se entende que a capacidade para compreender as ações do outro depende de um "espelhamento"9 dessas ações em meu próprio sistema motor, é possível então defender que esses problemas do

\footnotetext{
${ }^{9}$ Essa concepção é reforçada pela descoberta dos "neurônios-espelho", no início dos anos 1990. Esses neurônios são ativados na execução de uma tarefa e na visualização da mesma tarefa realizada por terceiros, especialmente em atos intencionais ou com conteúdo emocional. Desta forma, estariam envolvidos com a empatia, a compreensão de intencionalidade e a imitação. Desde o final dos anos 1990, pesquisadores passaram a investigar a possível relação entre autismo e diminuição da atividade desse sistema neuronal, o que estudos iniciais têm confirmado (Ramachandran; Oberman, 2006).
}

Rev. Nufen: Phenom. Interd. | Belém, 11(1), 194-214, jan. - abr., 2019. 
movimento atingiriam a intersubjetividade primária em sua constituição. Isso explicaria as dificuldades de interação presentes nos autistas, suas limitações em imitar e perceber os sinais corporais de emoções e, talvez, a hipersensibilidade a estímulos, os movimentos repetitivos e a ecolalia. Gallagher deixa em aberto, contudo, uma importante questão: que tipo específico de anormalidades sensório-motoras estaria associado à origem do autismo, já que diversas crianças não autistas também apresentam problemas nessa esfera?

Outra questão não respondida integralmente pela teoria interativa, mas também não esclarecida pela teoria da mente, diz respeito à origem de diversos sintomas "não sociais" do autismo, como o espectro restrito de interesses, a preocupação com partes de objetos, a necessidade de uniformidade e as habilidades mnêmicas prodigiosas ou 'savants'. Para entendê-los, alguns teóricos cognitivos têm recorrido à "teoria da coerência central" (Frith e Happé, 1994; Happé, 2005), pela qual, no autismo, haveria a ênfase descontextualizada nas partes em detrimento do todo. Gallagher relê essa teoria com olhos de fenomenólogo, defendendo que a dificuldade de entender contextos supõe prejuízos diretos na intersubjetividade secundária, que depende da compreensão e interação contextual com o outro. Fora desse conjunto, a intencionalidade de um movimento corporal não pode ser decifrada, perdendo seu sentido pragmático e social.

\section{CONSIDERAÇÕES FINAIS}

As teses de viés fenomenológico permitem a crítica da concepção cognitivistacomputacional das origens da subjetividade, apontando sua "ontologia alienada" (Gipps, 2004), na qual uma mente "interior" exala crenças, pensamentos e intencionalidade, tendo uma relação puramente contingente com a dimensão "exterior" e corporificada da existência humana. Em contrapartida, a fenomenologia oferecerá a matriz teórica que enfatiza os alicerces corporais, pré-reflexivos e intersubjetivos da vida mental, entendendo que a compreensão social - ou sua ausência, como no autismo - habita antes o registro da percepção e da ação do que o da cognição.

Para Leslie, Baron-Cohen, Frith e demais cognitivistas, dependemos de teorias e inferências para acessarmos o registro escondido do mental; para a fenomenologia, pensamentos, emoções e intenções já são expressos e compreendidos nas condutas explícitas, permitindo a sintonia mútua que funda a sociabilidade humana. Só quando se toma como ponto de partida indivíduos isolados é que é preciso elaborar uma grande maquinaria para entender como se tem acesso ao interior da mente alheia. Mas quando o registro intersubjetivo já está dado desde o início, pode-se dispensar a necessidade epistemológica de explicar o processo pelo qual os seres entendem as mentes dos outros ou as próprias mentes, indo direto às experiências e fatos fenomenológicos (Gipps, 2004). É a isso que McGeer (2004) se refere quando afirma que a "riqueza fenomênica da experiência" depende 
da amplitude da abertura ao mundo. É ao mundo que o sujeito deve se ater quando quer saber algo sobre suas experiências sensoriais, e é a ele que deve retornar, por via da memória ou da imaginação, se deseja autoconhecimento.

Desta forma, o fenômeno autista ganha uma nova chave de leitura, acima de dicotomias como mente e corpo, cérebro e psiquismo, afetividade e cognição, por meio da qual é possível compreender os sintomas do quadro - estereotipias, restrição do repertório de interesses, isolamento social ou falta de comunicação - como estilos distintos de abertura ao mundo, derivados de atipias na instalação da intersubjetividade. Para Gallagher - mas também para os demais fenomenólogos e mesmo para cognitivistas corporificados, como Klin et. al. - há modos variados pelos quais "o corpo molda a mente" desde os primeiros anos de vida, resultando em formas distintas de organização da experiência subjetiva corporificada, sendo o autismo uma delas.

Acreditamos que essa abordagem permite avanços na teoria com potenciais reflexos na prática com crianças, adolescentes e adultos com autismo. Do ponto de vista empírico, a clínica do autismo vai ao encontro de qualquer tese que coloque em destaque a dimensão sensório-motora. Um dos fenômenos que salta à vista de qualquer profissional, num primeiro contato com crianças autistas pequenas, não é a ausência de teoria da mente, mas o fato da motricidade estar, em algumas, no registro da hipoatividade e isolamento, e, em outras, no da hiperatividade. Por que deveríamos considerar isso como reflexo de falhas cognitivas básicas, e não como algo primário e fundamental no âmbito da própria corporeidade?

\section{REFERÊNCIAS}

Baron-Cohen, S. (1997). Mindblindness: an essay on autism and theory of mind. Massachusetts: MIT Press, 1997.

Baron-Cohen; Leslie, A. M.; Frith, U. (1985). Does the autistic child have a 'theory of mind'? Cognition, 21, 37-46, 1985.

Baron-Cohen; Leslie, A. M.; Frith, U. (1986). Mechanical, behavioural and intentional understanding of Picture stories in autistic children. British Journal of Developmental Psychology, 4, 113-125.

Elsabbagh, M., Divan, G., Koh Y. J., Kim, Y. S., Kauchali, S., Marcín, C., Montiel-Nava, C., Patel, V., Paula, C. S., Wang, C., Yasamy, M. T., Fombonne, E. (2012). Global prevalence of autism and other pervasive developmental disorders. Autism research, 5 , 160-179.

Fodor, J. A. (1983). The modularity of mind: an essay on faculty psychology. Cambridge, Massachusetts: MIT Press. 
Frith, U.; Happé, F. (1994). Autism: beyond 'theory of mind'. Cognition, 50, 115-132.

Gallagher, S. (2004). Understanding interpersonal problems in autism: interaction theory as an alternative to theory of mind. Philosophy, Psychiatry \& Psychology, 11(3), 199-217.

Gallagher, S. (2005). How the body shapes the mind. New York: Oxford University Press.

Gallagher, S; Zahavi, D. (2008). The phenomenological mind: an introduction to philosophy of mind and cognitive science. New York: Routledge, 2008.

Gipps, R. (2004). Autism and intersubjectivity: beyond cognitivism and the theory of mind. Philosophy, Psychiatry \& Psychology, 11(3), 195-198.

Grandin, T. (2005). A personal perspective of autism. In Volkmar, F. et al. (Ed.) Handbook of autism and pervasive developmental disorders. $3^{\text {rd }}$ edition. New Jersey: John Wiley \& Sons, pp. 1276-1285.

Happé, F. (2005). The weak central coerence account of autism. In Volkmar, F. et al. (Ed.) Handbook of autism and pervasive developmental disorders. $3^{\text {rd }}$ edition. New Jersey: John Wiley \& Sons, pp. 640-649.

Hill, A. P., Zuckerman, K., Fombonne, E. (2014). Epidemiology of autism spectrum disorders. In Volkmar, F. et al. (Ed.) Handbook of autism and pervasive developmental disorders. $4^{\text {th }}$ edition. New Jersey: John Wiley \& Sons, pp. 57-96

Kanner, L. (1943). Autistic disturbances of affective contact. Nervous Child, v. 2, 217-250.

Klin, A., Jones, W., Schultz, R.; Volkmar, F. (2005). The enactive mind, or from actions to cognitions: lessons from autism. In Frith, U.; Hill, E. L. Autism: mind and brain. New York: Oxford University Press, pp. 127-159.

Leslie, A. (1987). Pretense and representation: the origins of 'theory of mind". Psychological Review, 94(4), 412-426.

McGeer, V. (2004). Autistic self-awareness. Philosophy, Psychiatry \& Psychology, 11(3), 235-251

Nadesan, M. H. (2005). Constructing autism: unraveling the 'truth' and understanding the social. London, New York: Routledge

Premack, D.; Woodruff, G. (1978). Does the chimpanzee have a theory of mind? The Behavioral and Brain Sciences, 4, 515-526

Ramachandran, V. S.; Oberman, L. M. (2006). Broken mirrors: a theory of autism. Scientific American, 295(5), 39-45

Tager-Flusberg, H. (2001). A reexamination of the theory of mind hypothesis of autism. In Burack, J. A. et al. (Ed.). The development of autism: perspectives from theory and research. Mahwah: Lawrence Erlbaum Associates, pp. 173-193.

Teitelbaum, P., Teitelbaum, O., Nye, J., Fryman, J., Maurer, R. G. (1998). Movement analysis in infancy may be useful for early diagnosis of autism. Proceedings of the National Academy of Sciences of the United States of America, 95(23), 13982-13987

Tooby, J.; Cosmides, L. (1997). Foreword. In Baron-Cohen, S. Mindblindness: an essay on autism and theory of mind. Massachusetts: MIT Press, pp. xi-xviii. 
Trevarthen, C. (1977). Communication and cooperation in early infancy: a description of primary intersubjectivity. In Bullowa, M. (Ed.) Before speech: the beginnings of human cooperation. Cambridge: Cambridge University Press, pp. 321-347.

Trevarthen, C.; Hubley, P. (1978). Secondary intersubjectivity: confidence, confiding and acts of meaning in the first year. In Lock, A. (Ed.) Action, gesture and symbol: the emergence of language. London: Academic Press, pp. 183-229.

Zahavi, D.; Parnas, J. (2003). Conceptual problems in infantile autism research: Why cognitive science needs phenomenology. Journal of Consciousness Studies, 10 (9-10), 53-71.

\section{NOTAS SOBRE O AUTOR:}

Rossano Cabral Lima - Professor adjunto e vice-diretor do Instituto de Medicina Social da Universidade do Estado do Rio de Janeiro. E-mail: rossanolima1@gmail.com

Recebido em: 18/08/2018. Aprovado em: 05/04/2019. 